\title{
Education for All Open for Business? Public Goods vs. Private Profits
}

\author{
Alexandra Draxler
}

\section{Introduction}

Sustainable Development Goal (SDG) 4 and its related targets (UNGA, 2015b) contain admirable commitments, although many specifics about what it will take to fulfil them must be hammered out over time and according to context. However, as analysts have pointed out, there are contradictory underlying philosophies in the goals and supporting documents, so that what is left unsaid will be a significant influence as partners make their decisions going forward (Wulff, 2017; VanderDussen Toukan, 2017; Kumi et al., 2014). The Education 203 o Declaration (World Education Forum, 2015) goes part of the way in spelling out the respective roles of the public and private sectors, but those roles are formulated somewhat inconsistently. The Declaration makes mention in six places of the crucial role of the state in regulating various aspects of education. On the other hand, the private sector is given a metaphorical seat at the public policy table throughout, similar to the overall 2030 SDG agenda, positing contradictory expectations about the role of business in the education sector. For example, the assumption that embedding market-based value judgements into goals for the future of humanity will not corrupt the latter is unproven. The assumption, which is repeated several times in Goal 17 , that private funding will contribute substantially to filling any financing gap, is also unproven. Finally, the assumption that all potential partners will embrace inclusive public policies by contributing to equity is likewise unproven.

Target $4.1^{1}$ is unambiguous about the commitment to provide free and equitable education for all at both primary and secondary levels, system-wide tasks for which the vast majority of private entities are structurally uncommitted and unsuited.

On the basis of both the underlying philosophical contradictions embedded in the goals, including Goal 4, and the probable practical consequences of increased private sector involvement in the provision of basic education, this chapter will examine some of the hidden benefits to the private sector that are embedded in the goals, and the way in which for-profit provision of

(C) KONINKLIJKE BRILL NV, LEIDEN, 2020 | DOI: 10.1163/9789004430365_007 
education is likely both to distort the goals' stated objectives and hamper their achievement.

While it can be legitimately pointed out that for-profit education in developing countries is a tiny fraction of education supply, there is evidence (Steiner-Khamsi \& Draxler, 2018) that market ideology is permeating public policy and action beyond the limited market-based institutions (Stiglitz, 2018). Similarly, the 'data revolution' for stimulating and benchmarking progress toward meeting the SDG goals will undoubtedly have the effect of steering policy and public management in directions that can easily be measured. We saw this with the Education for All (EFA) process (Riddell, 2007). As technology becomes a larger part of the education landscape, it would be disingenuous to imagine that policymakers would not look to the budget for teachers to find the funds to cover the additional investments needed. Finally, equity can only be assured by public authorities and a watchful citizenry. Marketbased solutions are at best complements to public goods but cannot assure them.

Both development assistance and national public spending for education have declined over recent years and will likely continue to do so. Meeting the education targets would, on the contrary, require greatly increased spending, and the implication of both the agenda and background documents is that the private sector is expected to make up much of the financing gap (UNGA, 2015; International Commission on Financing Global Education Opportunity [Education Commission], 2016). Meanwhile, as David Archer and Tanvir Muntasim point out in Chapter 8, the private sector is focused principally on education supply as a business opportunity worth some US $\$ 4.4$ trillion. There is no documented plan for substantial independent private financing of education that would contribute to the benchmarks of national spending. Since, historically, private investment in public education depends substantially on public subsidy (Colclough, 1996), and there is no evidence that this will change in the future, the potential for distortion of the goal through capture of public funds by private entities is real (Lewin, 2013).

The implied financing partnerships between public and private sectors laid out in the 2030 Agenda and the Addis Ababa Action Agenda (including for reaching the targets of Goal 4) are not only unrealistic but worrying in their assumption that the two sectors both prioritise the common good of all (UNGA, 2015a, $2015 \mathrm{~b}$ ). It goes without saying that governments and business have structurally different priorities, and while there are exceptions, as a rule these priorities do not seamlessly mesh into 'win-win' situations (Murgatroyd \& Sahlberg, 2016). To adapt Stiglitz's image, the convergence of globalisation, technology, and market liberalisation has put the growth of inequality on steroids (Stiglitz, 2018), 
and this trend can only be fuelled as more and more private actors influence policy and action.

An example of convergence of interest but divergence of objectives is the push toward early childhood care and education (ECCE) expressed in Target 4.2. The Universal Declaration of Human Rights (UN, 1948) states the right to free elementary and fundamental education. It would be naïve in the extreme not to acknowledge that the fact that since ECCE is not explicitly mentioned as free, the business opportunity for expanding private and for-profit preprimary education has contributed to the motivation of private sector entities to be extremely supportive of ECCE. How they will contribute to the target, besides focussing on families with the means to pay for ECCE, is less clear.

This chapter looks at three interlocking ways by which the education goal and targets will be vulnerable because of the implicit assumption that motivations of both the public and private sectors will converge. The vulnerabilities will likely be expressed in unmet financial needs, distortion of spending for programmes, projects that cannot go to scale, and capture of public funds to support privately conceived innovations that do not have equity as their core objective. Many private sector entities have been determinedly promoting policies and practices that are primarily aimed at generating new markets and profits, and only incidentally, if at all, contributing to free and equitable education for all. While the SDGs themselves contain many references to the central role of the public sector in education for all, the supporting documents and institutions hedge their bets by referring frequently and insistently to things like the 'unprecedented range of public \& private parties in policy creation and implementation' (OECD, 2017b). The door is everywhere open for business (Kumi et al., 2014).

The three interlocking policy trends, promoted heavily by market-oriented interests are:

- promotion of technology as a corrective for deficiencies in contemporary teaching and learning;

- internationally designed, standardised benchmarking and monitoring of learning processes and outcomes; and

- tolerance and/or encouragement of for-profit provision of both compulsory and noncompulsory education.

Each of these has its place in well-conceived and regulated education systems that aim for free and equitable education for all. But they can also engender perverse effects that challenge system-wide success of SDG 4. Many of the side effects of market-based reforms of public services, including education, take decades to emerge and then decades to correct. 
Capture of public policy and funding (national and international), purportedly in the name of choice, efficiency and measurability distorts public spending, increases inequality, and progressively guts public education as it simultaneously subsidises corporate profit. The three interlocking trends seem to constitute a perfect storm for both progressively weakening the public sector and reinforcing the hold of private actors on education policies and the public purse.

The pressure to privatise significant portions of education policy and delivery, exemplified by the triad above, is gaining strength in many countries in the Global South, including for example Argentina, Brazil, India, Kenya, Liberia, Pakistan, and Peru (Verger, Fontdevila, \& Zancajo, 2016), following a model heavily promoted in a handful of OECD countries and accompanied by aggressive lobbying by corporations and market-oriented philanthropies (Barkan, 2011; Martens, 2017). Many corporations describe education as one of the last lucrative economic activities that has not yet been fully mined (Gutstein, 2012; Verger et al., 2016). When Rupert Murdoch gave his speech, Education: The Last Frontier, to a forum in Paris, his vision was of a massive influx of technology into education processes (Murdoch, 2011). That, of course, is the gold standard for generating profit: standardisation and high volume.

A narrative of generalised failure of public education (Murgatroyd \& Sahlberg, 2016; Stevenson \& Wood, 2013) is used to prop up the unproven claim that market-based reforms can do better to improve access, quality, and efficiency overall. Following the view by some decision-makers and users of education that education is a positional rather than a public good, there is a real and widespread demand for ever-increasing echelons of private education and private tutoring for some parts of the population.

Standardisation of testing and therefore of classroom processes does not of itself improve learning, rather it eventually impoverishes scope, diversity, and pertinence of learning (Archer, 2014). It is, however, convenient and profitable for corporations. International benchmarking has high opportunity costs and negligible proven benefits for individual learners. The widespread use of technology in classrooms has not demonstrated cost-effectiveness in learning (Glewwe \& Krafft, 2014) so much as its lucrative nature for technology industries. Recent funding trends and donor policies are resulting in backtracking from the objective of free universal basic education toward a model that shifts costs to households who are willing or constrained to pay.

Over the last few years, a rich and informative body of scholarly analysis has emerged on the subject of private sector involvement in education, which is called variously, privatisation, marketisation, the global education 
reform movement (GERM), and the global education industry, among others (Verger et al., 2016; Barkan, 2018; Aslam, Rawal, \& Saeed, 2017; Steiner-Khamsi \& Draxler, 2018). This chapter's purpose is to use a summary overview of the topic to attempt to tease out what marketisation may mean for progress toward SDGs.

As with privatisation of other public services, perverse effects are not immediate but build up over time. In countries such as the USA and the UK, where market-based reforms go back to the 1980s, there is ample research about negative side effects: inequality in spending and outcomes is growing, teacher disaffection is high, and teacher shortages are widespread.

The subject of market-based reform of education is highly ideologically fraught and, in the end, places in opposition two different philosophies on the purpose of education. These opposing philosophies exist uneasily side-by-side in the SDGs (VanderDussen Toukan, 2017). The shift in power relationships between governments and nonstate actors, which is currently accelerating, will threaten the optimistic assumption that with good will all actors can work together for a better educational world.

\section{Some Side Effects of Learner-Centred Philosophies of Education}

During the 196os, two very different visions of education converged on a key belief, which is that teachers are significant obstacles to needed evolutions in education. Philosophers such as Bourdieu (1970), Freire (1970), Illich (1971), and Reimer (1971) claimed that schooling and teachers contribute to perpetuating social reproduction, inequality, and submissiveness. For these thinkers, reworking education processes to pass on to learners more initiative and control was therefore logically the only path to individual empowerment, liberation from a conservative past, and creation of social mobility.

Human capital theorists (Becker, 1993; Schultz, 1961) and subsequent advocates of an economically utilitarian conception of education also saw teachers as obstacles rather than mediators for progress, but from a different angle. For them, since education processes focused on practical outcomes and the creation of human capital for mainly economic ends, one necessarily should look at free human interaction in classrooms with suspicion. In this view, teacher-controlled pedagogy seemed to be the frail and random element of the learning process. The logical shift to making education more predictable and therefore closer to manufacturing in nature would necessarily involve intervening in teacher autonomy. The fact that stricter controls could also reduce the required level of qualifications, and therefore costs, was not always openly 
acknowledged as a desirable by-product of reform. Following on this logic, with learning evaluated increasingly as a 'set of distinct, measurable competencies', teachers can be reduced to being 'deliverers of agreed upon curriculum' (Murgatroyd \& Sahlberg, 2016, p. 3).

These two threads obviously run through very different ideological visions of education. They nevertheless seem each to have contributed to an implicit contemporary position that the outcomes of education are principally the responsibility of the individual teacher and learner. On the one hand, shifting responsibility toward individuals can indeed be viewed as a form of liberation from hierarchical and conformist governance mechanisms, which has long been the mainstream view of philosophers of education, including the radical philosophers of the 196os and 1970s. However, the same shift can facilitate putting too much responsibility, and even blame, on teachers and learners for inequalities of achievement that are directly attributable to factors outside the school system, such as socioeconomic status, financing, health, segregation, language of instruction, and so on. Calls for individualised learning have arrived simultaneously in many countries with the use of standardised tests to measure competencies, which limit the impact of individualisation. In other words, when predictability and measurability in the learning process are judged to be the best guarantors of quality, blame can be assigned for failure to meet predefined standards. Inevitably a pernicious hierarchy of winners and losers is established, with the losers being the culprits.

Beginning principally in the United States several decades ago and now spreading in both wealthy and poorer countries, the narrative of failing schools has developed into a commonly accepted truth (United States, National Commission on Excellence in Education, 1983; Ravitch, 2013; Barkan, 2018). It has been used both to shift attention away from the extra-school factors that lead to low results and high dropout, and to promote the notion that the solution is for parents to be able to shop around for private or public schools deemed by them to be preferable, paid for in various ways by public money. This market-based notion of 'choice' has been successfully promoted as a method of improving education generally, in spite of the fact that there is no evidence that this is happening (Musset, 2012).

So, we are facing tolerance of the Darwinian view that competition and a free market will do the education job better than public policies, and that success and failure in learning achievement can be explained by individual choices and effort. Although simultaneously reducing the agency of teachers through more scripted materials and standardising testing could seem to be in conflict with individual responsibility, it fits in neatly with the manufacturing approach whereby processes and outcomes are standardised, and quality 
control of the line workers (teachers) and the final product (graduates) is a process of rejecting items that are dissimilar to the desired result. Hardly coincidentally, such a view of education also presents the optimum business model for supply of services at every level (Davis, 2016).

\section{Technologies in Education}

Since the 196os, successive technological advances have been touted as providing needed solutions for almost every perceived educational problem, whether related to inputs, processes, or outcomes. They are proposed as means of enhancing access in situations of teacher shortage, freeing learning from the constraints of space and time, making learning materials more reliable through standardisation, making evaluations comparable, individualising learning, limiting the roles of teachers in the name of eliminating human error, across-the-board management, and of course promising cost-effectiveness (Draxler \& Haddad, 2002). Many of these solutions are conceived along the line of manufacturing models, with the technologies enabling a reliable, uniform, and predictable outcome, that is, acquisition by learners of a set of measurable and predefined skills. The range of products developed and sold to schools and universities has been very broad as technologies have evolved: radio and 'interactive' radio, overhead projectors, various types of recording equipment, television, whiteboards, computers, tablets, and smart phones. Distance, online, and blended learning have come to occupy a significant place in the higher education landscape and are poised to make inroads in basic and postbasic education all over the world.

Based on the self-evident observation that some teachers do not perform according to legitimate expectations of time on task, relationships with learners, and quality of instruction, the notion of using technologies to compensate has appeal. Teacher salaries are by far the principal recurrent cost of education. However, a rich literature of research shows that the principal in-school factor influencing learning outcomes is qualified and motivated teachers (EFA GMR Team, 2015). Similarly, massive open online courses (MOOcs) and similar offerings have dramatically high dropout rates unless they are combined with tutoring by humans (Laurillard \& Kennedy, 2017). For-profit higher education institutions, including virtual ones, use a business model based on reducing personnel costs and increasing numbers of students. No studies show longterm, across-the-board gains in learning outcomes from the use of technologies in classrooms in countries where they are most widely used (OECD, 2016b). 
Education is one of the last relatively untapped sources of profit for large corporations. Historically, education has been a fragmented, labour-intensive activity with the main private sector opportunities being infrastructure and learning materials in the form of textbooks. While profit can be extracted from both, technological progress has opened the possibility of the production of huge volumes of standardised learning materials. The education technology market in the US is worth over US $\$ 8$ billion and growing. With less than $2 \%$ digitisation worldwide, the latest estimate of the worth of the market is already US $\$ 5.2$ trillion (United States, Department of Education Office of Planning Evaluation and Policy Development, 2010).

Although technologies are now ubiquitous in schools and universities in wealthy countries, so far, little of the promise has materialised, ${ }^{2}$ and certainly educational spending has not gone down (OECD, 2016b). The main beneficiaries of the boom in the use of technologies in teaching and learning have been the producers of the hardware and software. Many of the biggest aid donors and contributors to international organisations are also countries with large technology industries. Countries have historically provided a significant portion of aid in a manner that favours their domestic industries, through export of goods and services to recipient countries (Nowak-Lehmann et al., 2009). Technologies for education are no exception; building of trust and acceptance that technologies will improve learning at an ultimately lower cost in aid-recipient countries brings a huge parallel benefit in terms of exports from donor countries. Processes

The SDGs quite rightly emphasise the need for data to facilitate informed monitoring and decision-making of progress toward the goals. Indeed, the Secretary General of the United Nations created a special group to look at the potential and need for data as part of the SDG processes (IEAG, 2014). The 232 global SDG indicators (UN DESA, 2018a), of which 11 pertain directly to education, are all national-level indicators that are useful for measuring progress overall but have shortcomings in identifying national and regional disparities, weak spots, and decentralised management tools. The need to generate and use robust data-based evidence at all levels of education is not in question. Nonetheless, all endeavours have both opportunity costs and perverse outcomes or side effects. In this case, the opportunity costs of developing and updating 
internationally comparable data are likely to be high in the poorest countries, effectively prioritising this information over both implementation and other needed indicators of quality, inequality, and groups with special needs.

Similarly, efforts to develop internationally comparable tools of measuring learning, such as the Programme for International Student Assessment (PISA) and now PISA for Development (PISA-D), the Learning Metrics Task Force, and the Early Grade Reading Assessment (EGRA), do not find unanimous favour with educators and scholars (Archer, 2014; Gorur, 2016; Sorensen, 2015) precisely because of what is seen by some as reductionist approaches that narrow curriculum, place heavy burdens on educators, and encourage ranking. Other criticisms stem from the top-down nature of the conception of international measurement systems, their lack of democratic accountability and pertinence in some situations, and finally the often-confidential way in which ranking criteria are developed (Andrews et al., 2014). The eye-catching nature of ranking has been demonstrated to influence education policies as governments publicly commit to moving up, but with unclear results on learning (Fischman et al., 2019).

Furthermore, the debate about ownership of large sets of data is not benign. Until recently, most internationally comparable data on learning outcomes have been publicly generated and publicly owned. However, the collaboration of Pearson in the conception and execution of the next round of PISA could be the first stage in an ominous development: private creation and ownership of international data about students, learning outcomes, and education processes. There is also a real danger that the indicators, pleasing as they may be internationally, cannot adequately inform policies and practice in national contexts (Ahmed, 2014).

Standardising assessment is only the first stage of internationally standardising learning that facilitates the generation of reliably comparable data. In the US, where standardised multiple-choice testing is both ubiquitous and the object of significant dissatisfaction among teachers and parents (Hagopian, 2014), such assessment has narrowed the curriculum so much that writing is barely taught, and an estimated $20 \%$ of first-year higher education students have to take remedial courses. Many never learn to write properly (Maguire, 2016). Teaching and learning through highly standardised and scripted methods, such as those developed in the US and used by Bridge Academies in Kenya, are proudly reported to mean that each child in each school is following an identical 'learning' process at any given time (Education International and Kenya National Union of Teachers, 2016).

The standardised testing market is lucrative, valued at US $\$ 1.7$ billion annually in the US in 2012 (Chingos, 2012). While in financial terms this sum does 
not amount to more than several percentage points of education spending in the US, for developing countries widespread testing by commercial companies would obviously take a bigger proportion of budgets and a substantial financial outlay. Nevertheless, standardised testing and the corollary standardisation of the curriculum have huge commercial advantages that are now being widely pursued beyond OECD countries. The Bridge example is only one of many chains ${ }^{3}$ that are now seeking to get footholds in places where demand for private education is high and public education is struggling to accommodate every child, let alone improve quality.

As already mentioned, standardised international data invite ranking, which has many possibly pernicious effects. The first is that ranking is the most eye-catching aspect of data, and so the one that gets the most public attention. As a consequence, it tends to take on priority status with decision-makers. Another is that ranking of schools and universities has the opposite effect of improving performance: those with information and means flock to the highly ranked institutions, reinforcing and often adding to inequality (Andrews, 2016).

\section{5}

\section{Marketisation}

All international agreements and bodies since the creation of the United Nations and Bretton Woods institutions followed the lead and direction of the Universal Declaration of Human Rights on education, directing school education to be not only free but a prime responsibility of governments. ${ }^{4}$ However, about 30 years ago, a notion began to gain traction (Draxler, 2008) that the private sector, including corporations, has strong potential to contribute to education policy, management, and financing, and therefore to contribute to meeting the goals and targets of the Jomtien agreement (World Conference on Education for All, 1990) and now the SDGs. The entry point was the seemingly obvious requirement to diversify and amplify sources of financing to achieve universal education. Reinforcement came from neoliberal economics that revere market principles and excoriate government regulation and control. Meanwhile public-private partnerships (PPPS) in the public works of developing countries, essentially a disguised form of public borrowing (Hall, 2015), became widespread in OECD countries and was gradually promoted by bilateral and multilateral development financing institutions, in spite of the absence of evidence of their contribution to the public good (Utting \& Zammit, 2006). Expanding programmatically from PPPs for infrastructure to include education as a legitimate area, the UN actively adopted collaboration 
with business as one mode of growing all facets of education (UN Global Compact, 2013; Global Compact, 2012).

In recent years, acceptance of PPP models has extended to the acceptance and welcoming of for-profit companies, often multinational, operating in developing countries at every level of education: policy, teacher training, creation and operation of institutions, and testing, always with the support of public sector resources. While philanthropy is certainly growing in volume and influence (van Fleet, 2012), net financial contributions to education by the for-profit private sector are so low that they are not being tracked. A new landscape of very wealthy philanthropic organisations has grown up during this period as well, often financed by the private fortunes of leaders of technologybased corporations in wealthy countries (Barkan, 2011). These philanthropists' approach to education mostly mirrors their views about the essential role of market forces in all things, and commitment to introducing private sector action into all spheres of public life. Private for-profit operators of education, even basic education, have found approval and even support from the World Bank (2013), bilateral donors (Right to Education Project [RTE] et al., 2015), and international think tanks (Education Commission, 2016; Ashley \& Wales, 2015).

Although the proponents for marketisation of education claim it is necessary for expanded access, meeting SDGs, quality, and efficiency, it has not, and probably cannot be demonstrated to deliver those outcomes (Lewin, 2013; Sahlberg, 2013; RTE et al., 2015). As Lewin suggests, the reaffirmed promise that no country with a credible plan would lack resources to universalise primary education can appear to be sabotaged by the very parties that can ensure this promise is kept, namely donors (Lewin, 2013). More importantly, there is little evidence that educational investment, additional to that of governments and households, has been created.

This chapter's focus is on compulsory education, where until now the central role of government in ensuring access and regulation has been recognised. Nevertheless, for-profit higher education is not only expanding rapidly but also is more difficult to regulate because of its transborder nature. The development of for-profit higher education has been somewhat chaotic, underregulated, and with little discernible contribution to quality. Absent sufficient regulation, there have been problems of all sorts, ranging from unrecognised diplomas, high costs, low relevance to the job market, and outright fraud (United States Senate Health Education Labor and Pensions Committee, 2012). There are important lessons to be learned from the sometimes-disastrous expansion of unregulated for-profit higher education, such as predatory practices that lead to high drop-out rates, low-value or worthless degrees, and high costs that lead 
to individual debt (United States Senate Health Education Labor and Pensions Committee, 2012) as business expands its reach into other levels of education.

While the literature around the SDGs, and the SDGs themselves, often emphasise the importance of the public sector, in reality, international organisations have joined the march toward privatisation in the name of short-term fixes to long-term problems (Martens, 2017). A rich body of research is now available on both the concept of privatisation and concrete experiences (Verger et al., 2016; Draxler, 2012b; Ginsburg et al., 2012). Where there is robust research on comparative learning outcomes between the public and the for-profit sector, outcomes are inconclusive or favour the public sector (Aslam et al., 2017; Wulff, 2017). The comparative costs and results are hotly contested between critics and supporters. What is not contested is that teachers in the private sector are almost uniformly less qualified and paid less. Turnover of teachers is generally higher than in the public sector. The most marginalised or difficult-to-teach students are either not accepted or are eased out. And over time, leaching of resources from the public purse will damage education for the majority. In countries such as the US, the UK, Sweden, and Australia, where there has been a big shift toward private education, consequences are mixed, with positive effects principally accruing to higher socioeconomic groups, costs being lower only when teacher pay goes down and inequalities of achievement increase (Andrews, 2016; Carnoy, 1998; Reid, 2015).

The critical analysis above both is based on and joins a long series of cautions by researchers and civil society organisations about the profit-seeking actions that are contributing to weakening public sectors all over the world, and that can dilute, derail, and delay achievement of quality education for all (Martens, 2017). Public education is under threat in the face of determined efforts by private sector entities to capture public subsidies for profit. New philanthropists, with market-oriented philosophies of education, often steer their funding to support both policies and programmes that validate their own philosophies of marketisation (Walker, 2015). The arguments for privatising education simply do not stand up system-wide over time in any country. What does stand up is the overwhelming profit motive that sees a technology- and data-driven education, with educators as part of the gig economy and the public sector as the assumer of risks. There is no evidence that the confluence of education standardised in its delivery and evaluation, and driven by business interests, can contribute to meeting the aims of quality education for all. In my view, 
the international community is overly optimistic about the power relationships between the public and private sectors and thus may be dozing its way to another disastrous side-lining of its stated goal of free quality basic education for all.

The SDGs cannot succeed without strong governments, committed to the public good. The declaration preceding the goals is an affirmation of noble values signed by 'we', that is, the governments concerned (UNGA, 2015 b). However, the implementation is described in terms of broad partnerships that may or may not emerge globally or more locally.

Indeed, there is strong demand by families for better education, often expressed as demand for private education in the absence of a sufficiently credible offering of public education. Even very poor people make huge, often untenable sacrifices to do what they see as best for their children. Not-for-profit private education is a long-standing part of the educational landscape and has existed, mostly harmoniously, alongside public education since the nineteenth century. For-profit education is a newer phenomenon, and although it is relatively small, except for higher education, it seems to be growing much more quickly than anyone could have imagined several decades ago. The desirable collective response is not to use public funds, either national or international, to assist in exacerbating the public-private divide but to invest more and more wisely in robust public systems. Both the economic and social health of societies depend on public goods. Measures that capture resources and capacity needed to build strong public sector responses to the education needs of the population may serve the few and the short term but will inevitably reduce service to many and damage the social fabric.

What is the way forward? I believe it lies in strong citizen pressure for democratic accountability, transparency about the use of public money to support private education - especially profit-making education - and an insistence that experimentation in education carried out with public money be firmly grounded in research, scalability, inclusivity, and transparency. It lies in bolder and more coordinated intentions and actions by development institutions to ensure that the for-profit entities with which they work are contributing to rather than draining from resources devoted to achieving SDG goals.

One of the perverse effects of pursuit of the EFA goals was arguably that the emphasis on school enrolments dimmed efforts to achieve equity and quality (Riddell \& Niño-Zarazúa, 2016; Draxler, 2012a). A looming consequence of the SDGs in terms of education worldwide is the capture of public funds to support commercial interests, whose long-term effects could be deeply damaging to quality, equality, and the public good. 


\section{Notes}

1 'By 2030, ensure that all girls and boys complete free, equitable and quality primary and secondary education leading to relevant and effective learning outcomes' (UNGA, 2015b).

2 The OECD report (2016) uses the word 'yet' 16 times to refer to the elusive promises of technology to improve learning at lower cost, that are, and have been for decades, just around the corner, but not 'yet' here.

3 E.g., APEC (Philippines), BRAC (Bangladesh), Omega (Ghana), GEMs Education (more than a dozen countries).

4 Article 26: (1) Everyone has the right to education. Education shall be free, at least in the elementary and fundamental stages. Elementary education shall be compulsory. Technical and professional education shall be made generally available and higher education shall be equally accessible to all on the basis of merit. (2) Education shall be directed to the full development of the human personality and to the strengthening of respect for human rights and fundamental freedoms. It shall promote understanding, tolerance and friendship among all nations, racial or religious groups, and shall further the activities of the United Nations for the maintenance of peace. (3) Parents have a prior right to choose the kind of education that shall be given to their children (UN, 1948). 